\title{
CONCEPÇÕES DOCENTES QUANTO AOS PROCESSOS DE FORMAÇÃO DE PROFESSORES: UM ESTUDO EXPLORATÓRIO
}

\author{
Ana Paula de Andrade Janz Elias (CIDES/PUC/PR)* \\ https://orcid.org/0000-0002-6494-9448 \\ Beatriz Maria Zoppo (GPTEM/UFPR)** \\ https://orcid.org/0000-0002-5246-0805 \\ Claudino Gilz (USF)*** \\ https://orcid.org/0000-0003-3463-272X
}

\section{RESUMO}

O objetivo da presente pesquisa qualitativa exploratória é analisar as concepções docentes da rede municipal de ensino de Curitiba em relação aos processos de formação de professores vivenciados por eles ao longo de suas carreiras profissionais. A análise dos referidos dados atesta para quatro diferentes constatações: docentes a demonstrar conhecimento sobre a relevância dos processos de formação inicial e continuada; docentes a não identificar, em um primeiro momento, contribuições oriundas da formação inicial à sua atuação em sala de aula; docentes a indicar pré-disposição à realização de novos cursos de formação continuada; e docentes a sinalizar determinada resistência em termos de ampliação da formação inicial devido às condições de trabalho a que são submetidos. Identifica-se a necessidade de novas pesquisas sobre a problemática, principalmente no que tange à pertinência de atividades de formação continuada alternativas aos docentes dessa rede municipal de ensino. Palavras-chave: Formação docente. Formação continuada. Educação básica. Escolas públicas.

Doutoranda em Educação pela Pontifícia Universidade Católica do Paraná (PUC/PR). Integrante do Grupo de Pesquisas sobre Tecnologias na Educação Matemática (GPTEM), do Grupo de Pesquisa em Inovação e Tecnologias na Educação (GPINTEDUC/ UFPR) e do Grupo de Pesquisa Criatividade e Inovação Docente no Ensino Superior (CIDES/PUC/PR). Coordenadora do Curso de Graduação em Pedagogia da Faculdade Fidelis. E-mail: anapjanz777@gmail.com

** Doutoranda em Educação pela Pontifícia Universidade Católica do Paraná (PUC/PR). Integrante do Grupo de Pesquisa Criatividade e Inovação Docente no Ensino Superior (CIDES/PUC/PR) e do Grupo de Pesquisa sobre Tecnologias na Educação Matemática (GPTEM/UFPR). Professora da Rede Municipal de Curitiba, desde 2009 encontra-se como diretora da escola. Professora colaboradora da Uninter na modalidade educação a distância (EAD). E-mail: beazoppo@hotmail.com

** Doutor em Educação pela Universidade São Francisco (USF). Professor da FAE Centro Universitário. Diretor-Secretário da Associação Franciscana de Ensino Senhor Bom Jesus. Integrante do Grupo de Pesquisa Rastros: História, Memória e Educação (USF). E-mail: E-mail: claudinogilz@hotmail.com 


\section{ABSTRACT}

\section{TEACHING CONCEPTIONS FOR TEACHER TRAINING PROCESSES: AN EXPLORATORY STUDY}

The purpose of this exploratory qualitative research is to analyze the teaching conceptions of Curitiba's municipal school system in relation to the processes of teacher training experienced by them throughout their professional careers. The analysis of these data attests to four different findings: teachers demonstrating knowledge about the relevance of the initial and continuing formation processes; teachers who do not initially identify contributions from the initial training to their classroom performance; teachers who demonstrate willingness to undertake new continuing education courses; and teachers who show some resistance in terms of expansion of initial training due to the working conditions to which they are subjected. The need for further research on the problem is identified, especially regarding the relevance of alternative continuing education activities for teachers in this municipal school system.

Keywords: Teacher training. Continuing education. Basic education. Public schools.

\section{RESUMEN}

\section{CONCEPCIONES DE ENSEÑANZA PARA PROCESOS DE EDUCACIÓN DE PROFESORES: UN ESTUDIO EXPLORATORIO}

El objetivo de la presente investigación exploratoria cualitativa es analizar las concepciones docentes del sistema escolar municipal de Curitiba en relación con los procesos de formación docente que han experimentado a lo largo de sus carreras profesionales. El análisis de estos datos atestigua cuatro hallazgos diferentes: maestros que demuestran conocimiento sobre la relevancia de los procesos de formación inicial y continua; maestros no identificar, al principio, las contribuciones de la formación inicial a su desempeño en el aula; docentes para indicar la voluntad de emprender nuevos cursos de educación continua; y maestros para señalar cierta resistencia en términos de expansión de la formación inicial debido a las condiciones de trabajo a las que están sujetos. Se identifica la necesidad de una mayor investigación sobre el problema, especialmente con respecto a la relevancia de las actividades alternativas de educación continua para los maestros en este sistema escolar municipal.

Palabras clave: Formación del profesorado. Educación continua. Educación básica. Escuelas publicas.

\section{Introdução ${ }^{1}$}

1 Esta pesquisa seguiu orientações propostas na Resolução CNS 466/12, como: (i) o respeito aos participantes em sua dignidade e autonomia e o esclarecimento a eles quanto os procedimentos da pesquisa, desde questões iniciais até o compromisso de divulgação da mesma; (ii) a ponderação entre riscos e benefícios; (iii) a garantia de danos previsíveis; (iv) a relevância social da pesquisa; (v) a adequação e fundamentação aos princípios e fatos científicos; (vi) a utilização de métodos adequados para responder às questões estudadas; (vii) a obtenção do termo de consentimento livre e esclarecido assinado pelos participantes da pesquisa; (viii) a garantia do bem-estar dos participantes; (ix) a utilização de procedimentos que garantam a confidencialidade e a privacidade dos participantes; ( $\mathrm{x}$ ) a utilização dos dados e materiais obtidos somente para o objetivo proposto. 
A presente investigação decorre de uma questão mobilizadora: de que modo divisar as concepções docentes quanto ao que diz respeito à formação de professores inicial e continuada? A predileção por um estudo exploratório foi, após diversas tratativas empreendidas, a que mais poderia trazer constatações a contento em termos de análise da referida problemática.

Mais do que angariar respostas pontuais a tal questão, o objetivo é ater-se devidamente a cada concepção docente esboçada pelos participantes e interlocutores da pesquisa, efetivos da rede municipal de ensino de Curitiba, em relação aos processos de formação de professores vivenciados por eles ao longo de suas carreiras profissionais.

A ideia de "concepção docente" emana de várias modulações conceituais, a saber: uma noção prévia do que consiste a trajetória formativa inicial de um docente em potencial; um saber embasado do que vem a ser o ofício de ensinar, tecer estratégias mais viáveis à aprendizagem de determinado conteúdo; uma pressuposição que se alinha, por exemplo, à ideia de ensino a partir das possibilidades biológicas e cognitivas próprias de cada etapa de desenvolvimento do corpo discente etc.

A educação sinaliza para concepções afins e recorrentes, tanto em relação à formação como ao trabalho docente, divisando-os - a princípio - como modos de acolher, conhecer, sentir, amar, sondar conhecimentos prévios, propor atividades investigativas, mediar aprendizagens e promover o desenvolvimento integral do ser humano.

A formação do professor é, por assim dizer, um processo que se inicia antes mesmo do período de matrícula e frequência em um curso de graduação. Também é um processo que se estende pelo menos durante todo o tempo que se exerce profissionalmente a docência. Processo esse, na presente abordagem, alvo de indagação e análise. Analisar a formação e o trabalho docente não é um intento investigativo simples, visto que leva a constantes desassossegos, inquietações e, consequentemente, incompletudes em termos de abordagem. Pressupõe compreender a educação, antes de tudo, como um conjunto de saberes e práticas que se instauram visando formar pessoas - tanto quanto possível - para a vida em plenitude. "A epistemologia que sustenta a formação de professores tem mais da atividade-fim da escolarização do que possamos supor em um primeiro olhar: a aprendizagem do adulto/ profissional que se coloca [...] em condição de aprendiz." (ESQUINSANI; ESQUINSANI, 2014, p. 146).

À formação e ao trabalho docente convergem as mais diversas teorias e pontos de vista, bem como convergem diferentes reestruturações da carreira. Reestruturações essas que guardam “[...] relação com a forma como os docentes são considerados na sociedade contemporânea e como eles próprios concebem seu trabalho e sua profissão" (OLIVEIRA, 2018, p. 48).

0 exercício da profissão docente emana, antes de tudo, de uma atividade que tem se modulado, pelos menos nos últimos quatro séculos, atravessada pelos imbricamentos científicos, econômicos, políticos, culturais, fabris, artísticos do que se denominou como modernidade (BERMAN, 2007). Imbricamentos esses não só geradores de avanços e progressos, mas também de engodos, anulações, conflitos, desigualdades, tensões, lutas, resistências e contestações.

Logo, o escopo do exercício da profissão docente, suas peculiaridades teóricas e práticas, não tem se constituído e nem se ampliado imune às modulações econômicas, políticas, culturais e tecnológicas de cada época histórica, inclusive de cada contexto cotidiano, de cada percurso existencial e formativo dos envolvidos com as atividades de ensino e de aprendizagem. Eis porque "[...] ter acesso ao modo como cada pessoa se forma é ter em conta a singularidade da sua história e sobretudo o modo singular como age, reage e interage com os seus contextos" (MOITA, 1992, p. 115). 
A presente pesquisa se desenvolve dentro de um conjunto de concepções sobre: a educação em si; os valores de uma determinada circunscrição sociocultural; os modos de ser dos sujeitos acadêmicos, suas histórias de vida; os percursos formativos, entre outros aspectos. Vale salientar que a formação e o trabalho docente não se restringem à qualificação profissional, mas contemplam as dimensões física, afetiva, intelectual, social, entre outras. Dimensão social, inclusive, pois, "ninguém se forma no vazio. Formar-se supõe troca, experiência, interações sociais, aprendizagens, um sem fim de relações" (MOITA, 1992, p. 115).

Formação é permeada de complexidades e, por isso, não se reduz a algo que se "tem" ou que se "recebe". Eis porque toda formação diz respeito a um processo educativo, cujos pressupostos implicam em interações, práticas, troca de ideias, pesquisas, aportes teóricos, debates, aprendizagens situadas em tempos e espaços delimitados e práticas (MOITA, 1992).

A temática "formação docente" já ocupa lugar significativo nas pesquisas desenvolvidas nas últimas décadas (GARCIA, 1999; GATTI, 1997; NÓVOA, 1992; NÓVOA, 1995; PIMENTA, 1999; ROMANOWSKI; WACHOWICZ; MARTINS, 2005). É possível encontrar citações delas em artigos publicados em anais de congressos, seminários e outros eventos, em livros publicados, em dissertações de mestrado, em teses de doutorado e em diferentes periódicos. Algumas dessas pesquisas consideram que o modelo de formação acadêmica adotado pode influenciar nas práticas docentes em sala de aula e, consequentemente, influenciar o processo de aprendizagem dos estudantes.

Zeichner e Antunes (2009) fizeram uma revisão a partir dos relatórios de um evento que aconteceu nos Estados Unidos que abordavam temas sobre a formação inicial de professores e sugeriram, já no ano de 2009, uma agenda de pesquisa com esta temática. Considerando que existe uma efetiva contribuição para o desenvolvimento profissional docente a partir de formações continuadas (também compreendidas como "formação em serviço"), nas quais identifica-se o objetivo de levar os professores a reflexões sobre as práticas que desenvolvem nos processos de docência, bem como à consciência coletiva (SIVIERI-PEREIRA; ANUNCIATO; SILVA, 2019) e, também considerando as formações inicias desses profissionais, segundo Masetto (2003, p. 11, grifo do autor) faz-se necessário examinar alguns aspectos, tais como:

- o alinhamento integrado entre a legislação educacional vigente, a implementação de políticas públicas, os sistemas de ensino em suas diversas instâncias (federais, estaduais e municipais), as instituições de ensino formadoras e as instituições com seus programas de admissão e a valorização dos profissionais a exercer o magistério;

- a necessidade de uma articulação constante entre prática e teoria, entre o ideário acadêmico-pedagógico e a realidade das experiências docentes em sala de aula;

- o estabelecimento de critérios à busca pela competência profissional docente, isenta de improvisações;

- a instauração de uma identidade docente como mediador e agente da transformação social;

a diminuição das dicotomias, fragmentações e lacunas que se estabelecem entre os cursos de graduação (licenciatura) e as práticas no espaço educacional, visto que nem sempre o exímio aluno em termos de notas expressivas de um curso de licenciatura (formação inicial) é o que, na sala de aula, 'sabe ensinar'.

Do ponto de vista histórico, pode-se perceber que diferentes paradigmas têm determinado a visão de mundo dos docentes e quanto cada um desses paradigmas influenciaram as áreas do conhecimento, suas concepções, tendências, abordagens. No século XVII, Descartes propôs um paradigma cartesiano que acabou fragmentando o conhecimento, pois adotava uma visão disciplinar. No século XX predominava um ensino voltado para o Modelo Fordista. Nesta época contemporânea, ainda é possível identificar a influência da visão newtoniana-cartesiana no contexto edu- 
cacional, na qual manifesta-se a predileção por um conhecimento funcional e utilitário (BEHRENS, 2007).

Contígua à predileção por um conhecimento funcional e utilitário, identifica-se na contemporaneidade a proposição a se compreender de forma integrada o mundo, os diferentes ambientes, as diferentes situações (MORAES; NAVAS, 2010). Proposição essa embasada na ideia de que os fenômenos, os seres vivos, os arcabouços de saberes produzidos pela humanidade ao longo de sua história, assim como todas as coisas, estão interligados e interdependentes, como em uma teia.

Do ponto de vista da formação de professores, trata-se da perspectiva holística a partir da qual a atuação do docente precisa ser repensada, assim como ressignificada a formação de tais profissionais (GARCIA, 1999). Ressalta-se, segundo tal perspectiva, a importância de o professor considerar que a sua atuação docente se encontra interligada e entrelaçada ao contexto social, aos avanços tecnológicos, à produção de novos saberes a respeito do ser humano, dos valores vigentes a embasar as relações humanas, as preocupações com o cuidado do meio ambiente, as escolhas por itinerários formativos que no presente e no futuro possam dar sustentabilidade econômica e profissional, entre outros.

Day (2001) salienta que o professor é um profissional que ainda trabalha de forma isolada e, para esse autor, o processo de ensinar exige um trabalho pelo menos minimamente emocional. Torna-se válido considerar que o docente pode evoluir enquanto profissional ao longo dos anos, pois, enquanto indivíduo, ele tem desenvolvido questões fisiológicas, pessoais, cognitivas e morais.

Nesse sentido, fica evidente a grande importância de ressaltar as pesquisas que destacam o docente como sujeito de sua própria história, estabelecendo, assim, vínculos entre a trajetória pessoal e profissional, dando sentido às experiências, crenças e valores construídos ao longo de toda vida. (SIVIERI-PEREIRA; ANUNCIATO; SILVA, 2019, p. 208).
À referida evolução, Garcia (1999) acrescenta, por sua vez, a necessidade de implantação de políticas nacionais centradas no ensino e na profissão docente. A formação do professor não pode reduzir-se a considerações de situações periféricas. Postula-se que ela vá além, a ponto de formar esse profissional, tornando-o hábil a assumir efetivamente o que lhe diz respeito em termos de responsabilidade social.

Considerando que a conscientização do professor sobre os diferentes processos de formação pelos quais ele passa ao longo de sua carreira profissional pode influenciar em sua prática pedagógica, o presente artigo tem como objetivo identificar as concepções de professores da Educação Básica da rede municipal de ensino da cidade de Curitiba que atuam em escolas públicas sobre os processos de formação e de trabalho docente. Neste viés, a seguinte questão norteadora foi levantada: quais seriam as concepções docentes da Educação Básica que atuam na rede municipal de ensino de Curitiba quanto ao que diz respeito à formação de professores inicial e continuada?

Para responder à questão norteadora, foi realizado uma pesquisa qualitativa com viés exploratório. A pesquisa contou com a participação de 23 professoras/sujeitos da pesquisa, e os dados levantados são discutidos na sequência deste texto.

\section{A formação docente}

Um dos elementos intrínsecos ao tema da presente pesquisa diz respeito à compreensão da formação e do trabalho docente como uma instância de interações humanas. Interações humanas porque emanam de um trabalho docente "[...] sobre e com outrem" (TARDIF; LESSARD, 2005, p. 7), que passaram a se delinear há cerca de quatro séculos, em meio aos processos instrutivos e socioculturais potencializados pelo fenômeno da modernidade.

Um desses processos instrutivos e socioculturais potencializados pelo fenômeno da modernidade é o que se denomina como di- 
versidade, presente "dentro" e "fora" da sala de aula. Para ROMANOWSKI (2006, p. 121-122):

A sala de aula é um ambiente de diversidade, uma vez que abriga um universo heterogêneo, plural e em movimento constante, em que cada aluno é singular, com uma identidade originada de seu grupo social, estabelecida por valores, crenças, hábitos, saberes, padrões de condutas, trajetórias peculiares e possibilidades cognitivas diversas em relação à aprendizagem.

E quando se fala em interações humanas em meio a processos e espaços formativos atravessados pela diversidade, se pode afirmar que elas consistem, antes de tudo, em um conjunto de atividades inerentes ao instruir, ao aprender e até mesmo ao entreter o corpo discente: “[...] a escolarização repousa basicamente sobre interações cotidianas entre os professores e os alunos. Sem essas interações a escola não é nada mais que uma imensa concha vazia" (TARDIF; LESSARD, 2005, p. 22).

O trabalho "sobre" e "com" outrem não pode ser compreendido como qualquer outro labor. Pressupõe habilidades para mobilizar afetividades, linguagens, empatias, resistências, saberes, juízos de valor e a própria personalidade dos envolvidos: "A docência é um trabalho cujo objeto não é constituído de matéria inerte [...], mas de relações humanas com pessoas capazes de iniciativa e dotadas de uma certa capacidade de resistir ou de participar da ação dos professores." (TARDIF; LESSARD, 2005, p. 35).

Um dos pressupostos inerentes à formação docente está vinculado a formas históricas de articulação do trabalho em sala de aula. Articulação essa sequer isenta das influências oriundas das mudanças socioculturais, das polarizações políticas, das oscilações econômicas, dos avanços tecnológicos e das fragmentações da subjetividade ocorridas nas últimas décadas. A formação docente não é um processo circunscrito ao período de um curso acadêmico de licenciatura, ela é uma necessidade constante e implica em um processo de interação entre instituição formadora, pessoas e práticas (AMARAL; CAVALCANTI-NETO, 2016).
A expectativa de melhoria das práticas docentes pressupõe abertura e disposição à reflexão das ações desenvolvidas em sala de aula com base em teorias afins, pois a reflexão atrelada à teoria é que viabiliza o alcance de um conjunto de transformações das práticas docentes (SELINGARDI; MENEZES, 2017).

Entende-se o professor como elo principal entre a aprendizagem escolar e o aluno, pois o modo como esse profissional atua em sala de aula possibilita a construção de conhecimento por parte dos alunos. Conforme pontuam Gatti, Barreto e André (2011, p. 26), "O(a) professor(a) é o(a) ator(atriz) que está no centro do trabalho educacional institucionalizado, envolvido indissoluvelmente nas relações educativas".

Nesse sentido, o docente necessita de atualização constante frente às demandas que surgem com o passar dos anos nos diferentes contextos educacionais, pois “[...] o exercício da profissão de professor transcende o mero discurso ou os acordes da formação inicial [...]" (ESQUINSANI; ESQUINSANI, 2014, p. 144). Tal atualização pode auxiliar esse profissional a atuar na interface do planejamento das atividades de ensino, dos saberes inerentes ao contexto de sua prática pedagógica, do contexto sociocultural dos alunos e da condução de suas aulas. Isto, levando em conta as múltiplas estratégias metodológicas, bem como as estratégias avaliativas (CUNHA, 2004).

Dessa maneira, a formação docente inclui a troca e interação com seus pares, a participação em cursos, seminários, oficinas e ainda a participação em grupos de estudos dentro ou fora da escola que contemplem seus anseios profissionais. Inclui também, segundo Romanowski, Wachowicz e Martins (2005), a relação do que foi supracitado com:

a) o contexto sócio-histórico no qual novas exigências são determinadas para a organização da escola;

b) as finalidades e os determinantes da prática profissional do professor; 
c) o saber dos professores, resultante do processo vivenciado nos cursos de formação inicial e continuada;

d) o saber docente adquirido na prática profissional;

e) os saberes sobre os docentes oriundos das pesquisas que examinam a prática pedagógica;

f) os saberes forjados nas lutas de classe;

g) e a profissão do professor como prática social.

É comum acontecerem discussões nas quais a pauta é o que foi citado anteriormente, relacionado à qualidade do ensino e à ligação dela com a formação docente. Day (2001) faz uma crítica a essas discussões e ressalta que, quando se tem essa concepção em relação à formação docente, as políticas públicas direcionam suas formações para os processos de ensino, o que faz com que elas se tornem meros locais de repasses de técnicas para ensinar os professores a ministrarem suas aulas. Tal modelo de abordagem de desenvolvimento profissional pode ser considerado simplista e inviável, pois prevalece o sistema e ignora o professor como mediador dos processos dentro do ambiente escolar. Esse modelo de formação docente tem como um de seus pressupostos uma formação contínua com foco no conteúdo e no desenvolvimento de estratégias "[...] relativas à organização da sala de aula, ao ensino e à avaliação e, quando necessário, ao desempenho de papéis de liderança" (DAY, 2001, p. 85).

Tão importante quanto os professores terem domínio "[...] da ciência, técnica e arte da mesma, ou seja, possuam competência profissional" (GARCIA, 1999, p. 22), é a aprendizagem e o desenvolvimento de uma atuação docente autônoma e crítica. Ao considerar que seu trabalho docente se dá em uma sociedade cada vez mais complexa e exigente, o professor auxilia seus alunos a agirem com autonomia e criticidade no ambiente escolar e também fora dele.

Garcia (1999) entende que a formação docente objetiva a melhoria da qualidade de ensino, mas não se resume só a isso. 0 autor ressalta que a formação docente é um processo que acontece de forma sistemática e organizada e que deve levar a uma reflexão, a um aprimoramento da atividade docente, e não apenas ao processo de "aprender a dar aula". Sinaliza alguns princípios importantes que devem ser considerados no momento de formação de professores:

a) Compreensão de formação como um processo contínuo;

b) Formação como integradora de processos de mudança, inovação e desenvolvimento curricular;

c) Formação que leva em conta os processos de desenvolvimento organizacional da escola;

d) Formação integradora entre currículos de disciplinas acadêmicas à formação pedagógica dos professores;

e) Formação capaz de integrar teoria e prática;

f) Formação que leva a compreender a congruência entre conhecimento didático e o conhecimento pedagógico a ser transmitido;

g) Formação capaz de reconhecer o professor como ser individual;

h) Formação capaz de proporcionar momentos de indagações e reflexões pelos professores.

Ante o pressuposto de que o ser humano não nasceu pronto, Esquinsani e Esquinsani (2019) realçam que a formação docente, em especial a continuada, é intrínseca à condição de ser professor. É intrínseca, visto que dela necessita para se perfazer existencialmente como pessoa, como ser histórico e como ser social a partir das aprendizagens que vai obtendo imerso às diversas atividades do seu cotidiano acadêmico e profissional e do fazer pedagógico.

Day (2001) concebe a formação docente como desenvolvimento profissional. 0 autor salienta que o desenvolvimento profissional do professor pressupõe levar em conta os as- 
pectos emocionais, psicológicos e sociais que contribuem no encorajamento ou desencorajamento de sua aprendizagem profissional. Para o desenvolvimento de um projeto profissional de professores, recomenda a articulação de três aspectos, a saber:

a) o saber-fazer e as experiências dos professores;

b) o conhecimento, a competência e a capacidade profissional;

c) as fases de desenvolvimento dos professores.

É com base na articulação dos três aspectos supracitados que, segundo Day (2001, p. 114), os professores terão disponibilidade

[...] para refletirem, de forma sistemática, sobre seu pensamento e sua prática e sobre os contextos que estes ocorrem. Podem querer preparar-se para desempenhar uma nova função, renovar-se através de uma aprendizagem aprofundada sobre seu conhecimento pedagógico ou científico [...]

A obtenção do conhecimento pedagógico ou científico não se dá de modo neutro. De tal processo decorrem influências as mais diversas. De acordo com Behrens (2007, p. 439), "os paradigmas da ciência influenciam todas as áreas do conhecimento, em especial a Educação, e por consequência, a formação dos professores". A pesquisadora realça que esses paradigmas influenciam a ação docente adotada pelo profissional, podendo ela, no entanto, ser modificada ao longo de sua trajetória. As pesquisas desenvolvidas pela autora e seu grupo de pesquisa Paradigmas Educacionais e Formação de Professores (PEFOP) focam na educação superior, visto que acreditam estar no âmbito do Ensino Superior a possibilidade de renovação da atuação docente nos seus mais variados segmentos e níveis de ensino.

Entretanto, mais do que promover uma formação continuada que proporcione a reflexão, é relevante levar em conta a realidade de cada professor. Não se pode planejar uma formação considerando o grupo de professores com conhecimento homogêneo. Cada professor tem sua própria experiência profissional, bem como sua própria experiência de vida, as quais não devem ser desprezadas. É preciso refletir a partir dessas experiências pessoais e profissionais de tal maneira que os momentos formativos se tornem interessantes e atentem para as reais necessidades dos professores, visando à ampliação dos conhecimentos por parte desses profissionais.

Diferentemente das práticas tradicionais de formação, que não relacionam as situações de formação com as práticas de sala de aula, as experiências mais eficazes para o desenvolvimento profissional são aquelas que estão baseadas na escola e que se inscrevem dentro das atividades cotidianas dos professores. (VAILLANT; MARCELO, 2012, p. 196).

Conforme os autores supracitados, ressaltase a importância de as formações não estarem dissociadas da prática de sala de aula. Elas devem articular a teoria, relacionando-as com as práticas de sala de aula. É viável que os professores estabeleçam sentido às atividades que desenvolvem nos processos da docência, ampliando seus subsídios teóricos, tendo a possibilidade de reelaborar e (re)significar seus saberes.

Há, a princípio, dois paradigmas a determinar a prática docente: o conservador e o inovador. A formação na perspectiva da concepção conservadora privilegia o saber-fazer, ou seja, a formação do professor centrada exclusivamente no treino e no domínio do conteúdo.

A qualificação profissional conservadora recebe também a designação de capacitação que adquire força nas empresas, nas indústrias e nas escolas. A capacitação tem como finalidade o acompanhamento e a qualificação de recursos humanos para repetir tarefas, em especial pela crescente e contínua evolução das tecnologias. (BEHRENS, 2007, p. 444).

Já o paradigma inovador aponta para uma interconexão de diferentes abordagens, visões e abrangências educacionais. Nesse paradigma predomina uma nova necessidade de formação e qualificação contínua que abordem uma 
"visão crítica, reflexiva e transformadora" (BEHRENS, 2007, p. 445) da educação. Entretanto, nesse movimento paradigmático, a formação deve voltar-se ao processo e não a um produto em si, visto que a formação dos professores passa por diferentes períodos: inicial, contínua ou continuada.

Nesse viés, o papel das instituições é oferecer encontros contínuos que promovam a reflexão individual e coletiva da ação docente. A docência precisa ser compreendida em sua totalidade, na qual teoria e prática são indissociáveis e podem gerar uma ação efetivamente transformadora. 0 desafio está em oferecer e instigar os docentes a inovar sua prática pedagógica, que contemple as aprendizagens para a vida: “[...] o desenvolvimento profissional baseado na reflexão exige encontros periódicos e contínuos para dar voz aos professores e assim provocar o processo individual e coletivo de transformação" (BEHRENS, 2007, p. 444).

Outro aspecto relevante a ser destacado é o que diz respeito ao incentivo do docente em participar de formação docente para enriquecer sua trajetória profissional:

0 reconhecimento dos docentes da educação básica como profissionais essenciais ao país passa pela oferta de carreira digna e remuneração condizente com a formação deles exigida e ao trabalho deles esperado. Não se pode camuflar isso com sofismas que não contribuem com a profissionalização dos professores e a construção de sua identidade profissional com características comuns valorizadas. (GATTI; BARRETO; ANDRÉ, 2011, p. 139).

Mesmo diante de diferentes perspectivas sobre a formação docente, constata-se, pelos autores citados anteriormente, o quanto convergem para a compreensão da formação docente como um processo que ocorre durante a sua trajetória de qualificação profissional. No entanto, caso esse profissional não se sinta valorizado, sequer se sentirá estimulado a participar de formações complementares e de aprimoramento à sua formação inicial.

\section{Aspectos metodológicos}

Esta pesquisa de cunho qualitativo e caráter exploratório buscou responder à questão norteadora: quais seriam as concepções docentes da Educação Básica que atuam na rede municipal de ensino de Curitiba quanto ao que diz respeito à formação de professores inicial e continuada?

Em uma pesquisa qualitativa de cunho exploratório, os pesquisadores buscam compreender tanto o contexto como o ambiente no qual os participantes estão inseridos (CRESWELL, 2007). Assim sendo, a presente pesquisa se deu a partir das inquietações dos pesquisadores, devido à estreita relação deles com as escolas públicas da Rede Municipal de Ensino de Curitiba.

O convite para a participação na pesquisa foi feito de forma pessoal a professores que participavam de quatro instituições públicas que atendem alunos do Ensino Fundamental I. Dentre os convidados, em um primeiro momento, apenas 10 professoras decidiram participar da pesquisa; após nova conversa, mais 13 docentes aceitaram colaborar com o levantamento de dados para a construção deste texto, totalizando 23 sujeitos.

A referência aos participantes será no gênero feminino, pois são todas mulheres. Estas professoras têm entre 28 e 56 anos. Dentre as participantes, 18 têm formação em pedagogia e 5 dessas têm uma segunda formação de nível superior: serviço social (uma professora); letras (duas professoras); matemática (uma professora); e direito (uma professora). Duas professoras indicaram a seguinte formação para o nível de graduação: letras (uma professora); normal superior (uma professora). Duas professoras comentaram que têm especialização e uma pontuou que tem mestrado. As participantes também indicaram o tempo de atuação delas como docentes (Quadro 1). Com a intenção de manter a identidade destas professoras em sigilo, aqui elas são denominadas por P1, P2, P3... P23. 
Quadro 1 - Tempo na docência

\begin{tabular}{|c|c|}
\hline PARTICIPANTES & TEMPO DE DOCÊNCIA \\
\hline P1; P21; P23 & 1 a 10 anos \\
\hline $\begin{array}{c}\text { P2; P3; P4; P6; P7; P8; P10; P11; P12; } \\
\text { P13; P15; P16; P17; P18; P20; P22 }\end{array}$ & 11 a 20 anos \\
\hline P5; P9; P14; P15; P19 & 21 a 30 anos \\
\hline
\end{tabular}

Fonte: Elaborado pelos autores deste artigo.

A partir da análise de entrevistas semiestruturadas foi possível, com o suporte do software de análise de dados qualitativos ATLAS. ti, relacionar os dados coletados e agrupá-los em classes:

a) Concepção de formação docente - aqui as participantes tiveram a possibilidade de pontuar o que entendiam por este tipo de formação e quais suas concepções sobre processos de desenvolvimento profissional;

b) Características de uma formação docente - as professoras puderam emitir suas opiniões sobre as características que consideram importantes para um processo de formação;

c) Participação em formação docente - as professoras indicaram as formações das quais participaram. Essa classe permitiu validar o item (a) e identificar se a concepção que as participantes têm de formação docente tem efetiva relação com o que elas pontuaram anteriormente;

d) Predisposição para participação em novas formações docentes - aqui foi possível identificar se as professoras percebem que os processos de formação docente se constituem em algo que pode auxiliá-las em seu desenvolvimento e em sua atuação profissional.

Considerando o viés qualitativo exploratório, buscou-se elaborar um instrumento de pesquisa "capaz de captar, do Universo de Respostas, as respostas mais adequadas ou convenientes para a pesquisa" (PIOVESAN; TEMPORINI, 1995, p. 321). Ou seja, capaz de apreender, em outras palavras, as concepções das docentes da Educação Básica que atuam na rede municipal de ensino de Curitiba quanto ao que diz respeito à formação de professores inicial e continuada.

\section{Discussão e análise dos resultados}

Ao serem questionadas sobre suas concepções acerca da formação docente, as 23 participantes desta pesquisa indicaram diferentes aspectos:

a) P1 e P18 pontuaram que entendem por formação docente a formação integral que tiveram, desde o curso de magistério, o curso de graduação, até cursos de formação continuada que têm participado ao longo de suas carreiras profissionais;

b) P3 e P12 comentaram que entendem que a formação docente é composta por cursos de graduação; P12 ainda especificou o curso de pedagogia e de magistério superior;

c) 14 participantes (P2, P4, P5, P6, P7, P8, P9, P10, P11, P13, P14, P15, P17 e P19) indicaram que a formação docente é algo que compreende os objetivos da atuação do professor, os prepara para a compreensão de conteúdos, para a percepção e conhecimento de novas abordagens metodológicas e visa promover uma reflexão sobre a própria prática. É possível identificar nos excertos a seguir a concepção docente dessas professoras 
entrevistadas: "formação docente envolve práticas que trazem crescimento e aperfeiçoamento profissional: cursos, palestras, oficinas, estudos concentrados, práticas artísticas e culturais" (P4); "formação docente é aquela que ocorre durante toda a vida de um professor e que acontece de diferentes formas: cursos, oficinas, disciplinas isoladas, especializações" (P8).

d) três participantes comentaram sobre o aperfeiçoamento profissional, mas também indicaram que as formações devem ter foco nas necessidades dos estudantes e, ainda, devem atender as demandas sociais que transformam o contexto escolar (P16, P20 e P23);

e) uma participante apontou que as formações docentes devem ser práticas e voltadas para questões de dificuldades de aprendizagem dos estudantes (P21);

f) uma participante indicou que a formação docente é composta pela formação inicial e continuada. Para ela:

É algo em que se pretende preparar os profissionais para a sua atuação. Caso seja seu primeiro curso, ele tem a oportunidade de saber um pouco como funciona uma sala de aula. Se algo para aprimoramento, ele passa a ter mais conhecimentos para uma melhor atuação em sala. (P22).

Fica possível perceber aqui que apenas as participantes P1, P18 e P22 relacionaram a questão de formação docente, assim como fizeram Romanowski, Wachowicz e Martins (2005), com situações formais como cursos de Ensino Médio (como magistério), de graduação, de formação continuada ou outros eventos como seminários, cursos de extensão e oficinas. Contudo, apenas P1 e P18 indicaram todos esses momentos como partes de formação docente. Com isto, mostra-se a necessidade de perceber como o docente concebe sua profissão para poder levá-lo a ter uma visão mais holística de seu processo de formação, bem como de sua atuação.
Esse profissional precisa não somente de uma formação integral, conforme citam Moraes e Navas (2010); ele necessita compreender que sua formação é integral e contínua, e cada passo do percurso percorrido deve ser considerado para que ele reflita sobre sua atuação e interfira nos processos de ensino e de aprendizagem de forma mais efetiva.

Já as participantes P2, P4, P5, P6, P7, P8, P9, P10, P11, P13, P14, P15, P16, P17, P19, P20, P21 e P23 comentaram sobre as características da formação docente a partir dos objetivos que percebem que uma formação deve contemplar. A relação entre a formação docente e a atuação docente, conforme pontuado por Tardif e Lessard (2005), fica evidente a partir das colocações dessas professoras.

P16, P20, P21 e P23 sinalizam que as questões práticas de sala de aula e o desenvolvimento dos estudantes devem ser contemplados em processos de formações docentes. Tal concepção dessas professoras da Educação Básica que atuam na rede municipal de ensino de Curitiba corrobora com o que já afirmara Tardif (2008, p. 241): “O principal desafio para a formação de professores, nos próximos anos será o de abrir um espaço maior para os conhecimentos práticos dentro do próprio currículo."

Dessa maneira entende-se que as professoras da Educação Básica que atuam na rede municipal de ensino de Curitiba buscam uma formação que lhes possa trazer conhecimentos específicos para a sua prática profissional. Logo, os pressupostos teóricos e formativos da prática docente hão de se constituir predominantemente a partir do contexto social e das problemáticas em que vivem e atuam os professores, pois isto "poderia ser a chave de toque que acionaria uma nova postura metodológica" (GATTI, 1997, p. 57).

Os postulados que as professoras da Educação Básica que atuam na rede municipal de ensino de Curitiba apontaram como essenciais à formação docente em âmbito inicial e continuada foram as seguintes: 
a) As tratativas formativas precisam contemplar teoria, vinculando esta à prática (P1, P4, P5, P7, P8, P9, P10, P12, P13, P14, P15, P18, P19, P23);

b) Faz-se necessário considerar o contexto no qual os professores estão inseridos, bem como o entorno da escola (P2, P3, P4, P6, P7, P9, P14, P15, P16, P22, P23);

c) É relevante propor ideias inovadoras $\mathrm{e}$ criativas que possam ser aplicadas dentro de sala de aula (P2, P3, P4, P6, P11, P13, P17, P20, P21);

d) Possibilitar trocas entre os pares (P11, P15, P20, P23);

e) E, ainda, as professoras P10 e P23 indicaram que as formações docentes devem ser contínuas.

0 que foi pontuado no item a, quanto ao que é essencial a uma formação docente, é corroborado por Moita (1992) e por Amaral e Cavalcanti-Neto (2006). Estes autores apontam que a formação docente deve estar relacionada à prática desse profissional. Ministrar palestras, seminários, cursos ou outros espaços de formação docente sem abordar a prática de sala de aula pode levar o professor a uma reflexão, contudo, uma reflexão sem ação, e isto não promove movimento nos processos de ensino e de aprendizagem, ou seja, mantém a estrutura educacional estagnada.

As professoras P2, P3, P4, P6, P7, P9, P14, P15, P16, P22 e P23 citam a relevância que deve se dar ao contexto no qual os docentes estão inseridos. Cunha (2004) comenta que é válido avaliar o contexto porque assim pode-se ponderar sobre as estratégias metodológicas e avaliativas que o professor pode adotar em sala de aula. Nesta mesma perspectiva, P2, P3, P4, P6, P11, P13, P17, P20 e P21 indicam o foco na atuação do professor, de maneira que novas ideias sejam abordadas para nortear o trabalho do docente em sala de aula, sendo assim, essas professoras também percebem a necessidade de vincular as formações com as práticas docentes. Vincular a prática ao contexto social é efetivamente algo que pode contribuir para os processos de formação dos estudantes da atualidade, bem como para uma postura mais ativa e segura dos profissionais da educação.

A questão da continuidade colocada pelas participantes P10 e P23 é importante devido ao fato de estarmos em uma sociedade mais globalizada, e a formação do professor precisa contemplar aspectos que permeiem a criticidade, a reflexividade e as transformações, conforme pontuado por Behrens (2007), para atuar nesta sociedade de forma mais autônoma e crítica.

Quando questionadas sobre a disponibilidade em participar de novos cursos de formação docente, 7 participantes indicaram que não têm: P1, P3, P4, P12, P13, P16 e P17. Para P1, P4 e P12, a desvalorização do professor na atualidade faz com que elas não se sintam motivadas a participar de nenhum tipo de formação; a participante P3 comentou que já estudou bastante ao longo de sua carreira profissional e, como está próxima de sua aposentadoria, não percebe necessidade de realizar novos estudos; P17 ressalta que as formações apresentam discursos antigos e repetitivos.

Vale observar que os comentários das docentes P1, P4 e P12 estão intimamente relacionados às políticas públicas municipais adotadas no contexto atual, visto que o plano de carreira dos professores foi embargado, não proporcionando nenhum estímulo financeiro aos docentes a participarem de formações. Isso, inclusive, pode ser aferido na tratativa do poder executivo em julho de 2017, ao determinar a suspenção do plano de carreira dos servidores municipais de Curitiba, afetando diretamente a classe docente (LAZARO JUNIOR, 2017).

Mesmo diante desse cenário político, foi possível identificar a predisposição para participação de novos cursos de formação em 16 participantes (P2, P5, P6, P7, P8, P9, P10, P11, P14, P15, P18, P19, P20, P21, P22 e P23). As motivações para tal predisposição apresentadas pelas professoras da Educação Básica que atuam na rede municipal de ensino de Curitiba foram: 
a) ampliar, aprofundar e aprimorar conhecimentos e melhorar a atuação em sala de aula, além de investir no currículo (P2, P8, P15, P21 e P23);

b) melhorias da prática de sala de aula (P11, P18 e P22);

c) crescimento e aprendizado pessoal, bem como profissional (P19);

d) buscar ferramentas para construir e compreender as diferentes concepções pedagógicas (P14);

e) busca de estratégias inovadoras para as práticas pedagógicas (P10, P20);

f) troca de saberes e conhecimentos entre os pares (P5);

g) adquirir novas técnicas para auxiliar os estudantes na construção do conhecimento (P6, P7);

h) acompanhar os demais docentes que trabalham na mesma instituição escolar (P9).

É possível identificar nos apontamentos das professoras os anseios de adquirirem novos conhecimentos. Esses novos conhecimentos podem se relacionar e se integrar com conhecimentos que elas já possuem e podem dar-lhes um efetivo suporte para suas atuações dentro do contexto educacional.

Por fim, algumas professoras apontaram quais os temas de formação que ainda não tiveram a oportunidade de participar, mas que gostariam de ter contato futuramente:

a) educação inclusiva (P4, P14);

b) ensino de língua portuguesa (P5, P23); ensino de matemática (P5, P10, P19, P23);

c) ensino de ciências (P5);

d) uso de tecnologias digitais em sala de aula (P6, P10);

e) ensino de arte (P7);

f) ensino de história e sociologia (P7);

g) e, por fim, cursos que tratem de questões ligadas a dificuldades de aprendizagem (P21).

As demais participantes não destacaram o tema de seu interesse, ainda que se mos- trassem dispostas a participar de novas formações.

Nesse viés, é possível identificar que há nichos para auxiliar os professores em seu desenvolvimento profissional a partir de cursos de formação continuada. Embora não seja oportuno em nenhum momento acolher esse tipo de formação como uma atividade benéfica ao professor, sem antes avaliar qual concepção de formação continuada uma rede de ensino apresenta, bem como quais as necessidades dos profissionais que nela atuam, e, a partir dessas concepções, propor atividades e cursos afins.

\section{Considerações Finais}

As concepções docentes quanto ao que diz respeito à formação de professores inicial e continuada se constituem e se ampliam em meio ao cotidiano formativo e de atuação profissional. As concepções docentes se mostram, a cada instante, expressões genuínas do percurso formativo palmilhado e do saber pedagógico obtido no exercício da função, quase sempre mobilizado por pressupostos teóricos e escolhas metodológicas. É a partir de tais concepções e na relação com o contexto social em que vive que cada professor ensina e interage em sala de aula com seus alunos.

É visível que o contexto social mudou. A facilidade com que se tem acesso às informações contrasta com práticas docentes, ainda presentes, do século XIX, tais como memorizações e cópias. Diante do exposto, ressalta-se a importância de uma formação docente que contribua com os profissionais para atuar nesse contexto. Uma formação docente que considere a escola como a principal formadora de cidadãos críticos, reflexivos e atuantes de uma sociedade. Uma formação docente capaz de compreender o professor como um profissional que traz consigo apropriações de saberes e de experiências obtidas em sala de aula. Uma formação docente que favoreça ao professor exercer sua função com propriedade teórica e capaz de se fazer 
crítico e reflexivo sobre suas práticas. Uma formação docente que, desde a etapa inicial, dissemine a consciência de inacabamento e, por isso, aponte para o professor a necessidade de estudos complementares permanentemente.

Hoje, diante de um contexto mais globalizado, mais integrado, nos quais redes devem ser formadas pelas diferentes pessoas para uma ação mais consciente enquanto cidadãos, o docente necessita de preparo, pois é formador de outros cidadãos que já atuam ou irão atuar em uma sociedade com um novo paradigma.

Entende-se que a formação docente acontece em diferentes etapas do percurso profissional do professor e em cada etapa ela se define como algo permanente, que visa à consolidação da identidade do professor e da socialização das situações cotidianas vivenciadas pelos docentes e pelos demais atores que estão inseridos nas instituições escolares. Neste viés, a formação docente está relacionada a processos de análise de cunho crítico-reflexivo em relação às teorias e às práticas dos docentes no contexto escolar.

Pode-se afirmar que tanto a formação quanto o trabalho docente são permeados por complexidades e, por isso, apoiam-se em pressupostos que implicam na troca de ideias, na predisposição para o desenvolvimento de pesquisas, na articulação de aportes teóricos, na participação em debates e em interações com todos os envolvidos com o processo educacional, e que essas reflexões priorizem diálogos que ultrapassem a reprodução de ensino tradicional.

Existe a necessidade de diálogo para identificar as dificuldades enfrentadas pelos docentes e os anseios que eles têm em relação às atividades que exercem nas instituições de ensino que atuam. Foi possível identificar que existe uma predisposição por parte das professoras/ sujeitos desta pesquisa para o aprendizado, visando a continuidade de seus processos de formação. Os professores precisam de suporte para desenvolver suas atividades, destarte, as formações precisam ser inovadoras e atender aos anseios desses profissionais. A formação não deve acontecer com receitas prontas, mas sim construídas com esses profissionais dentro da própria escola.

Pensar a formação do professor a partir das necessidades dos docentes faz com que tenha maior relevância e maior impacto na atuação desses profissionais. Focar em uma melhoria na qualidade do ensino e pensar na aprendizagem do aluno são importantes ao planejar formações docentes, contudo elas não podem se resumir a isto, conforme já citou Garcia (1999). As formações devem considerar a continuidade, promover mudanças e inovações nas práticas pedagógicas, considerar o contexto no qual os professores estão inseridos, promover reflexões, diálogos e considerar a individualidade de cada profissional.

Possibilitar ao professor, por meio de pesquisas, como a que aqui foi apresentada, pensar sobre sua formação e sobre as necessidades que ele identifica que podem ser supridas por meio de formações continuadas, é possibilitar a esse profissional que ele se identifique enquanto protagonista em sua própria ação. Esse protagonismo pode beneficiar os processos de aprendizagem dos discentes e modificar os diferentes espaços de ensino nos quais atua.

Vale pontuar que a formação do docente pode ser promovida por diferentes profissionais da educação, por meio de políticas públicas, por formadores de professores, mas também pode ser pensada pelo próprio professor, que, reconhecendo sua identidade e sua importância para o âmbito social, tem a possibilidade de se planejar e investir em diferentes momentos de formação. Outro aspecto, não menos importante e que chama atenção, foi a fala das docentes que relataram estar desmotivadas a participarem de formação, não por não considerarem importante a formação, mas por não haver estímulo financeiro por parte da instituição.

Diante dos resultados, conclui-se que essa compreensão dos professores ao que se refere à formação docente continuada deve ser levada 
em conta para o planejamento e desenvolvimento de futuras formações. Entretanto, fazse necessário que outras investigações sejam realizadas, oportunizando que outros professores sejam ouvidos e que novas ideias sejam compartilhadas para que, assim, as formações impulsionem os docentes a participarem dessas com a motivação e o desejo de realimentar seus saberes e conhecimentos.

\section{REFERÊNCIAS}

AMARAL, E. M. R. do; CAVALCANTI NETO, A. L. G. Análise do processo de construção da prática docente de um professor de Ciências, a partir da perspectiva de sistema de atividades proposta por Engeström. ACTIO, Curitiba, v. 1, n. 1, p. 26-50, jul./ dez. 2016. Disponível em: http://periodicos.utfpr. edu.br/actio. Acesso em: 12 nov. 2019.

BEHRENS, M. A. O paradigma da complexidade na formação e no desenvolvimento profissional de professores universitários. Revista de Educação, Porto Alegre, ano XXX, v. 63, n. 3, p. 439-455, set./ dez. 2007.

BERMAN, Marshall. Tudo o que é sólido se desmancha no ar. Tradução de Carlos Felipe Moisés e Ana Maria L. Ioriatti. 5. impressão. São Paulo: Companhia das Letras, 2007.

CRESWELL, J. W. Projeto de pesquisa: métodos qualitativo, quantitativo e misto. 2. ed. Porto Alegre: Artmed, 2007.

CUNHA, M. I. A docência como ação complexa: o papel da didática na formação de professores. In: ROMANOWSKI, J. P.; MARTINS, P. L. O.; JUNQUEIRA, S. R. A. (org.). Conhecimento local e conhecimento universal: pesquisa, didática e ação docente. Vol. 1. Curitiba: Champagnat, 2004. p. 31-42.

DAY, C. Desenvolvimento profissional de professores: os desafios da aprendizagem permanente. Lisboa: Porto Editora, 2001.

ESQUINSANI, Rosimar Serena Siqueira; ESQUINSANI, Valdocir Antonio. Aprendizagem profissional e políticas para formação continuada de professores: um estudo de caso. Revista da FAEEBA-Educação e Contemporaneidade, Salvador, v. 23, n. 41, p. 139-147, 2014.

GARCIA, C. M. Formação de professores - para uma mudança educativa. Lisboa: Porto, 1999.

GATTI, B. Formação de professores e carreira.
São Paulo: Cortez, 1997.

GATTI, B. A.; BARRETTO, E. S. de S.; ANDRÉ, M. E. D. A. Políticas docentes no Brasil: um estado da arte. Brasília, DF: Unesco, 2011.

LAZARO JUNIOR, J. Plano de Recuperação: projeto congela carreira dos servidores. Notícias do legislativo. Câmara Municipal de Curitiba. $11 \mathrm{abr}$. 2017. Disponível em: https://www.cmc.pr.gov.br/ ass_det.php?not=27721. Acesso em: 08 out. 2019.

MASETTO, M. T. Competência pedagógica do professor universitário. São Paulo: Summus, 2003.

MOITA, M. C. Percursos de formação e de transformação. In: NÓVOA, A. (org.). Vidas de professores. Porto: Porto, 1992. p. 111-140.

MORAES, M. C.; NAVAS, J. M. B. Complexidade e transdisciplinaridade. Rio de Janeiro: Wak, 2010.

NÓVOA, A. (org.). Vidas de professores. Tradução de Maria dos Anjos Caseiro e Manuel F. Ferreira. Porto: Porto, 1992.

NÓVOA, A. (coord.). Os professores e a sua formação. Tradução de Graça Cunha, Cândida Hespanha, Conceição Afonso e José A. Souza Tavares. Lisboa: Dom Quixote, 1995.

OLIVEIRA, Dalila Andrade. A reestruturação da profissão docente no contexto da nova gestão pública na América Latina. Revista da FAEEBA-Educação e Contemporaneidade, Salvador, v. 27, n. 53, p. 43-59, 2018.

PIMENTA, S. G. (org.). Saberes pedagógicos e atividade docente. São Paulo: Cortez, 1999.

PIOVESAN, A.; TEMPORINI, E. R. Pesquisa exploratória: procedimento metodológico para o estudo de fatores humanos no campo da saúde pública. Revista de Saúde Pública, v. 29, p. 318325, 1995.

ROMANOWSKI, J. P. Formação e profissionalização docente. 2. ed. Curitiba: Ibepex, 2006.

ROMANOWSKI, J. P.; WACHOWICZ, L. A.; MARTINS, P. L. O. Saberes docentes e os determinantes da prática social. Diálogo Educacional, v. 5, n. 16, p. 11-23, set./dez. 2005.

SELINGARDI, G; MENEZES, M.V. M. Compreendendo o que é ser um professor reflexivo ante a ação pedagógica. ACTIO, Curitiba, v. 2, n. 3, p. 270-286, out./dez. 2017. Disponível em: http://periodicos. utfpr.edu.br/actio. Acesso em: 01 nov. 2019.

SIVIERI-PEREIRA, Helena de Ornellas; ANUNCIATO, Rosa Maria Moraes; SILVA, Ana Maria Costa. 
Formação continuada e identidade profissional na voz de docentes do Brasil e de Portugal. Revista da FAEEBA-Educação e Contemporaneidade, Salvador, v. 28, n. 55, p. 202-220, 2019.

TARDIF, Maurice. Saberes docentes e formação profissional. 9. ed. Petrópolis, RJ: Vozes, 2008.

TARDIF, M.; LESSARD, C. 0 trabalho docente: elementos para uma teoria da docência como profissão de interações humanas. Petrópolis, RJ: Vozes, 2005.
VAILLANT, D.; MARCELO, C. Ensinando a ensinar: as quatro etapas de uma aprendizagem. Curitiba: UTFPR, 2012.

ZEICHNER, K. M.; ANTUNES, C. Uma agenda de pesquisa para a formação docente. Revista Brasileira de Pesquisa sobre Formação de Professores, v. 1, n. 1, p. 13-40, 2009.

Recebido em: 13/12/2019 Aprovado em: 20/03/2020

(cc) DrY-NC Este é um artigo publicado em acesso aberto sob uma licença Creative Commons. 